\title{
Relationship between Serum Visfatin and Obesity in Lead-Exposed Obese Subjects and Patients with Osteoarthritis
}

\author{
Ahmad Tarik Numan ${ }^{*}$, Ali Mahmoud Al-Joda1, Nada Kadom Jawad ${ }^{2}$ \\ ${ }^{1}$ Department of Pharmacology and Toxicology, College of Pharmacy, University of Baghdad, Baghdad, Iraq \\ ${ }^{2}$ Department of Public Health, Al-Kindy College of Medicine, University of Baghdad, Baghdad, Iraq \\ Email: *ahmadt20002000@yahoo.co.uk
}

Received 29 November 2015; accepted 23 February 2016; published 26 February 2016

Copyright (C) 2016 by authors and Scientific Research Publishing Inc.

This work is licensed under the Creative Commons Attribution International License (CC BY).

http://creativecommons.org/licenses/by/4.0/

cc) (i) Open Access

\begin{abstract}
Aim: To evaluate the relationship between serum levels of visfatin, lead (PB) and cadmium (Cd) in obese male subjects with osteoarthritis (OA). Methods: A total of 40 obese males (age: 25 - 55 years; BMI $\geq 30$ ) participated in the study. They were subdivided into 3 groups; group $A, 10$ patients with $\mathrm{OA}$; group $\mathrm{B}, 15$ workers in gasoline filling stations; group $\mathrm{C}, 15$ obese subjects without any apparent other health problems or chronic diseases. After overnight fasting, blood samples were collected from all participants to evaluate blood levels of $\mathrm{Pb}, \mathrm{Cd}$ and $\mathrm{HbA1c}$, in addition to serum visfatin, lipid profile, glucose and total antioxidant state (TAS). Results: Obese patients with OA have significantly higher BMI value $(p<0.05)$ than the other groups. Obese gasoline station workers demonstrate highest blood lead levels compared to the other groups. Serum visfatin levels in obese subjects with $\mathrm{OA}$ were significantly higher than that reported in the other groups. Blood lead contents and serum visfatin levels were positively and significantly correlated in the three groups, and greatest correlation coefficient value (r) was reported in obese $0 \mathrm{~A}$ patients followed by obese gasoline station workers and healthy obese subjects, respectively. BMI in obese healthy subjects shows weak positive and non-significant relationship with serum visfatin levels, while highly positive and significant correlation was reported between these two markers in obese gasoline station workers. However, BMI values and serum visfatin showed weak negative and non-significant correlation with serum visfatin levels in obese $0 A$ patients. Conclusion: Serum visfatin levels could be key regulators of obesity and $\mathrm{OA}$, and an important partner with excessive environmental exposure to $\mathrm{Pb}$ in the pathogenesis of these disorders.
\end{abstract}

\section{Keywords}

Visfatin, Obesity, Osteoarthritis, Lead, Cadmium

\footnotetext{
"Corresponding author.
}

How to cite this paper: Numan, A.T., Al-Joda, A.M. and Jawad, N.K. (2016) Relationship between Serum Visfatin and Obesity in Lead-Exposed Obese Subjects and Patients with Osteoarthritis. Health, 8, 318-324. 


\section{Introduction}

Many reports highlighted direct signaling between subchondral bone and cartilage through the diffusion of mediators through the vasculature and microcracks [1]. This process enables transfer of soluble mediators that have the capability to modulate the functions of many cells at these sites [2]. During inflammatory conditions like osteoarthritis $(\mathrm{OA})$, the synovium may be involved in the communication process through releasing chemical mediators that involved in joint damage and bone remodeling [3]. Adipokines are soluble mediators, which mainly released by adipose tissue, can be also produced by the synovium and significantly involved in OA pathogenesis [4] [5]. These adipokines played a crucial role in many immune, inflammatory and metabolic processes, including potential involvement in low-grade inflammation reported in obesity and might contribute to the associated metabolic diseases; accordingly they could be suggested as effective players during OA associated with obesity and/or exposure to other related etiologic factors [6] [7]. Recently, many researchers were interested in the adipokines visfatin [8], which was synthesized by adipose and many other tissues, including synovium and cartilage [9]. Although scanty data was available regarding the role of visfatin in OA, its production by IL-1 $\beta$-stimulated OA chondrocytes has been previously reported [10]. Recently, extensive elevation in blood lead $(\mathrm{Pb})$ levels in mice was associated with increased food intake, body weight, total body fat, and the possibility of excessive production of visfatin cannot be ruled out [11]. Obesity and extensive exposure to $\mathrm{Pb}$ were among the risk factors for development of OA, and many reports have shown that adipokines could play an important role in the progression of OA [3] [12]. In the present study, we aimed to address the relationship between plasma visfatin levels and blood levels of $\mathrm{Pb}$ and cadmium, and other metabolic markers in OA patients and obese subjects.

\section{Methods}

In this non-randomized cross-sectional study, 40 obese males, who routinely attended the out-patient clinic, Al-Hilla Teaching Hospital were included, and have body mass index (BMI) $\geq 30$, calculated by dividing body weights over the square root of the body height; their age range was 25 - 55 years. They were categorized into 3 groups; the $1^{\text {st }}$ group includes 10 obese patients which have been already diagnosed by senior rheumatologist with osteoarthritis according to the ACR criteria [13]; $2^{\text {nd }}$ group includes 15 obese gasoline filling stations workers in Hilla City, Babylon who have a high chance to be exposed to heavy metals like $\mathrm{Pb}$ and $\mathrm{Cd}$. The last group includes 15 obese subjects with no clinically defined illness or history of chronic diseases, and exposure to $\mathrm{Pb}$ and $\mathrm{Cd}$ were highly excluded. Adequacy of sample size was checked online using Evan's Awesome A/B tool. The study was conducted during January-June 2015; the research protocol was approved by the local Research Ethics Committee at the College of Pharmacy, University of Baghdad, and informed signed consent was obtained from each subject before inclusion. The presence of any other pathologies like hypertension, diabetes and renal diseases was considered as an exclusion criteria. After reporting the demographic characteristics of each participant, fasting venous blood sample $(10 \mathrm{ml})$ was obtained, and $5 \mathrm{ml}$ was kept in plain tube, left to clot and centrifuged at $4000 \mathrm{rpm}$ at $4^{\circ} \mathrm{C}$ for $10 \mathrm{~min}$; the resulted serum was utilized for analysis of visfatin [14], total antioxidant capacity [15], lipid profile [16] [17] and fasting serum glucose levels [18]. The other $5 \mathrm{ml}$ aliquot of blood was kept in heparinized tube and utilized for analysis of HbA1c [19], Cd and Pb levels with atomic absorption spectrometric method [20].

\section{Statistical Analysis}

Data analysis was performed using SPSS 15.0 software. The differences between the groups were evaluated with ANOVA followed by Benferronis' post hoc test. The relationships between serum visfatin and other variables were assessed using the Pearson correlation analysis. The level of significance was accepted at $p<0.05$.

\section{Results}

Primarily, no significant differences were reported between the mean ages of the three groups. Table 1 shows that obese patients with OA have significantly higher BMI value $(p<0.05)$ than the other groups, which are not significantly different with each other in this respect. Blood lead levels are significantly different among the studied groups $(p<0.05)$, where the obese gasoline station workers demonstrate highest blood lead levels compared to the other groups, while the healthy obese subjects showed the least value of blood lead levels among the others (Table 1). However, measurements of blood Cd levels did not reveal significant differences among 
the three studied groups. Table 2 also indicates that serum visfatin levels in obese subjects with OA were significantly higher than that reported in the other groups, and the obese healthy subjects demonstrate the lowest serum visfatin level compared with others. Finally, Table 2 indicates that TAS values in healthy obese subjects were significantly greater than those reported in the other two groups, which are not significantly different with each other in this regard. In Table 2, serum levels of total cholesterol and LDL-c were significantly elevated in obese OA patients compared with that in other two groups, which showed no significant differences in this regard when compared with each other. Meanwhile, HbA1c and serum levels of TG, HDL-c, and fasting glucose were not significantly different among the three studied groups (Table 2). Correlation studies between blood lead contents and serum visfatin levels indicated that these two parameters were positively and significantly correlated in the three groups, and greatest correlation coefficient value (r) was reported in obese OA patients ( $r=0.7, p=0.02)$ followed by healthy obese subject $(r=0.68, p=0.005)$ and gasoline station workers $(r=0.54$, $p=0.039$ ), respectively (Figures 1-3). Figure 4 indicates that BMI in obese healthy subjects shows weak positive and non-significant relationship with serum visfatin levels $(r=0.19, p=0.49)$, while positive and significant correlation $(r=0.54, p=0.037)$ was reported between these two markers in obese gasoline station workers (Figure 5). However, BMI values and serum visfatin showed weak negative and non-significant correlation $(r=$ $-0.28, p=0.43$ ) with serum visfatin levels in obese OA patients (Figure 6).

Table 1. Body mass index (BMI), blood levels of $\mathrm{Cd}, \mathrm{Pb}$, and serum visfatin and total antioxidant capacity (TAS) levels in obese subjects with OA or exposed to heavy metals.

\begin{tabular}{cccccc}
\hline Groups & BMI $\left(\mathbf{k g} / \mathbf{m}^{2}\right)$ & Blood Pb $(\boldsymbol{\mu g} / \mathbf{d l})$ & Blood Cd $(\boldsymbol{\mu g} / \mathbf{d l})$ & S.Visfatin $(\mathbf{n g} / \mathbf{m l})$ & S. TAS $(\mathbf{m m o l} / \mathbf{l})$ \\
\hline Obese + OA $(n=10)$ & $35.8 \pm 3.5^{\mathrm{a}}$ & $19.8 \pm 1.6^{\mathrm{a}}$ & $0.26 \pm 0.03^{\mathrm{a}}$ & $53.0 \pm 8.2^{\mathrm{a}}$ & $0.98 \pm 0.15^{\mathrm{a}}$ \\
Pb-Exposed $(n=15)$ & $32.7 \pm 3.4^{\mathrm{b}}$ & $23.1 \pm 2.2^{\mathrm{b}}$ & $0.26 \pm 0.04^{\mathrm{a}}$ & $42.3 \pm 4.7^{\mathrm{b}}$ & $1.0 \pm 0.27^{\mathrm{a}}$ \\
Obese only $(n=15)$ & $32.0 \pm 2.3^{\mathrm{b}}$ & $17.3 \pm 2.0^{\mathrm{c}}$ & $0.23 \pm 0.04^{\mathrm{a}}$ & $30.9 \pm 3.2^{\mathrm{c}}$ & $1.8 \pm 0.47^{\mathrm{b}}$ \\
\hline
\end{tabular}

Values are presented as mean $\pm \mathrm{SD} ; n=$ number of subjects; values with non-identical superscripts (a, b, c) for the same parameter within the same group are considered significantly different $(p<0.05)$.

Table 2. Serum glucose, lipid profile and HbA1c levels in obese subjects with OA or exposed to heavy metals.

\begin{tabular}{ccccccc}
\hline Groups & Cholesterol $(\mathbf{m g} / \mathbf{d l})$ & TG $(\mathbf{m g} / \mathbf{d l})$ & HDL-c $(\mathbf{m g} / \mathbf{d l})$ & LDL-c $(\mathbf{m g} / \mathbf{d l})$ & Glucose $(\mathbf{m g} / \mathbf{d l})$ & HbA $\mathbf{1 c}(\%)$ \\
\hline Obese + OA $(n=10)$ & $215 \pm 18^{\mathrm{a}}$ & $183 \pm 13^{\mathrm{a}}$ & $48 \pm 6^{\mathrm{a}}$ & $129 \pm 16^{\mathrm{a}}$ & $102 \pm 8^{\mathrm{a}}$ & $6.6 \pm 0.5^{\mathrm{a}}$ \\
Pb-Exposed $(n=15)$ & $198 \pm 14^{\mathrm{b}}$ & $189 \pm 54^{\mathrm{a}}$ & $46 \pm 7^{\mathrm{a}}$ & $114 \pm 12^{\mathrm{b}}$ & $97 \pm 9^{\mathrm{a}}$ & $6.4 \pm 0.4^{\mathrm{a}}$ \\
Obese only $(n=15)$ & $193 \pm 12^{\mathrm{b}}$ & $176 \pm 55^{\mathrm{a}}$ & $49 \pm 7^{\mathrm{a}}$ & $109 \pm 12^{\mathrm{b}}$ & $70 \pm 8^{\mathrm{a}}$ & $6.3 \pm 0.4^{\mathrm{a}}$ \\
\hline
\end{tabular}

Values are presented as mean \pm SD; $n=$ number of subjects; values with non-identical superscripts (a, b, c) for the same parameter within the same group are considered significantly different $(p<0.05)$.

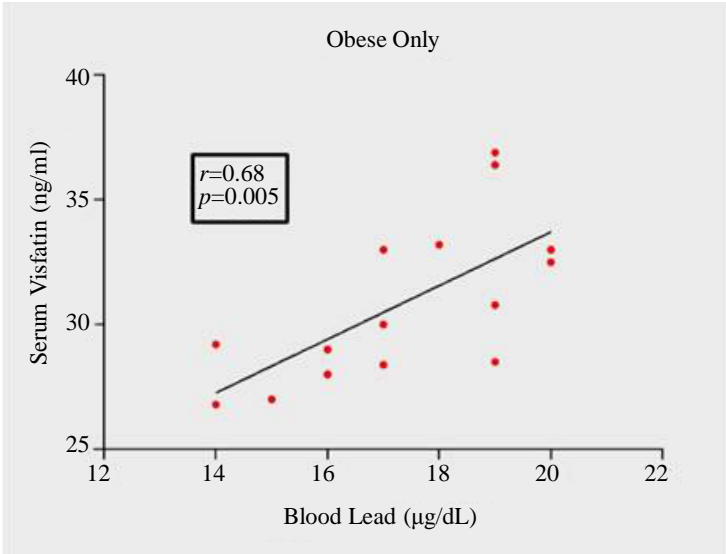

Figure 1. Correlation between blood lead concentrations and serum visfatin levels in healthy obese subjects. 


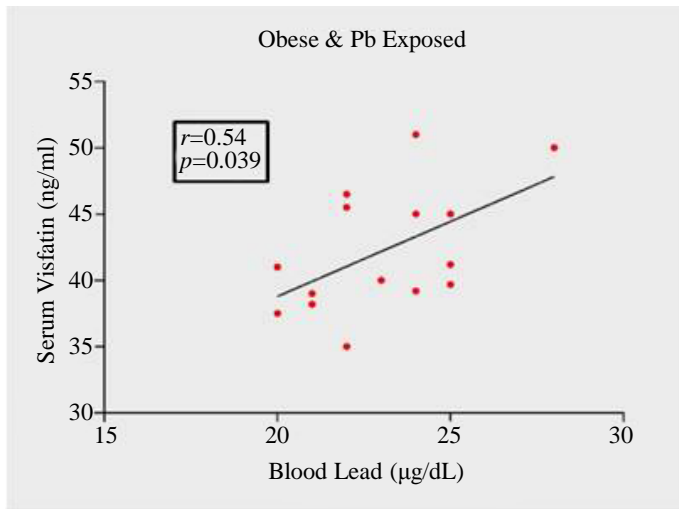

Figure 2. Correlation between blood lead concentrations and serum visfatin levels in obese gasoline station workers.

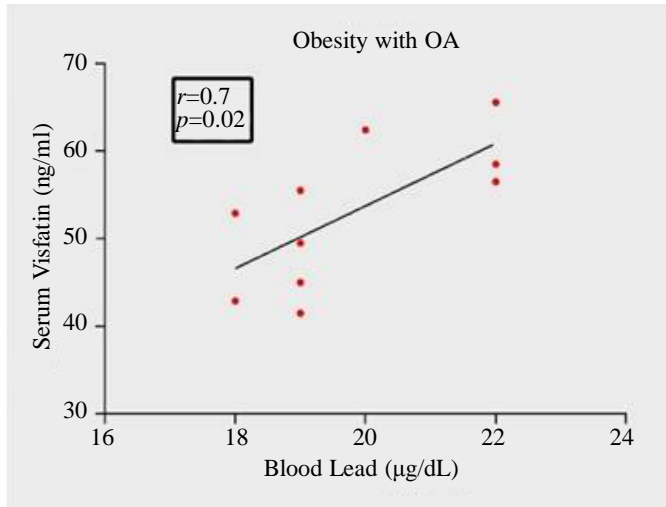

Figure 3. Correlation between blood lead concentrations and serum visfatin levels in obese subjects with OA.

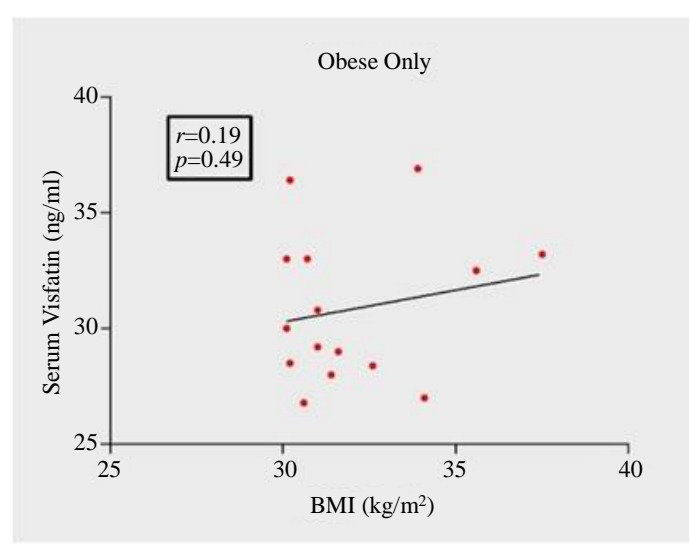

Figure 4. Correlation body mass index (BMI) values and serum visfatin levels in healthy obese subjects.

\section{Discussion}

Many reports indicated the involvement of visfatin in obesity and pathogenicity of OA. In the present study serum visfatin was significantly elevated in obese OA patients compared with healthy subjects, and many previous data points to visfatin as a pro-catabolic/pro-inflammatory factor rather than an anabolic factor. Obesity was 


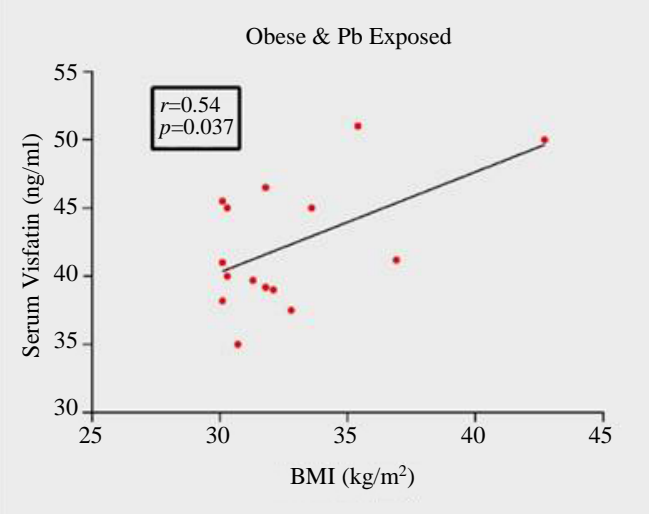

Figure 5. Correlation body mass index (BMI) values and serum visfatin levels in obese gasoline station workers.

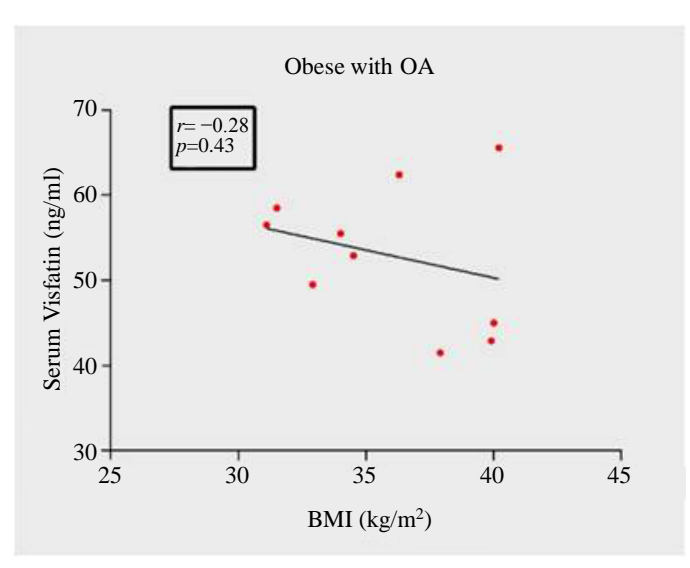

Figure 6. Correlation body mass index (BMI) values and serum visfatin levels in obese subjects with OA.

considered as one of the risk factors for $\mathrm{OA}$, and characterized by a low grade inflammatory state that may contribute to harmful effects in many organ systems. The precise metabolic pathways through which obesity contributes to joint structural damage involved aberrant adipokines expression with direct and downstream effects leading to the destruction and remodeling of joint tissue [21] [22], and many cytokines released from adipose tissues may influence OA though direct joint degradation or control of local inflammatory processes [23]. According to the Pearson's correlation results, the present study does not fully support the hypothesis that adipose tissue is the most important source of circulating visfatin. In this regard Berndt et al. did not show a relationship between plasma visfatin and visceral fat mass assessed by computed tomography scan [24], and macrophages of the adipose tissue can be other major source of visfatin [25]. Gasoline station workers are regularly exposed to many hazardous toxins and noxious substances including heavy metals like $\mathrm{Cd}$ and $\mathrm{Pb}$, and can lead to abnormal alterations in the functions of many vital organs. In the present study, the obese gasoline workers showed higher serum $\mathrm{Pb}$ levels compared with other obese subjects included in the study. Similar results were obtained in gasoline stations workers within other parts of Iraq [26]. In the present study, the high level of positive correlation between blood lead and visfatin clearly indicates that excessive environmental exposure to lead may predispose to excessive production of visfatin from many tissues. Currently, no study evaluates the relationship between elevated blood lead content and visfatin production, and this might be attributed to the oxidative stress state induced by elevated blood lead levels [27]. In experimental animals, elevated ROS generation damaged the joints matrix and highly correlated with experimentally-induced $\mathrm{OA}$ [28], and suppression by $\mathrm{Pb}$ of many antioxidant enzymes, including SOD and catalase [29], could be considered as aggravating factor and linked positively with excessive release of visfatin and the apparent decrease in TAS values, reported in the present study, may be 
considered as another support for this assumption. The other mechanism by which Pb may contribute to the pathogenesis of $\mathrm{OA}$ is through the increase in matrix metalloproteinase 13, associated with elevated cytokines production [30]. The current finding was limited by the small sample size and consequent inability to predict the exact etiology behind the reported changes. Taken together, the reported data in the current study represent a crude finding that need further supported evidence, and further studies highly suggested with larger samples to avoid the limitations of the current work.

\section{Conclusion}

Serum visfatin levels could be key regulators of obesity and OA, and an important partner with excessive environmental exposure to $\mathrm{Pb}$ in the pathogenesis of these disorders.

\section{Acknowledgements}

The authors thank University of Baghdad for supporting the project.

\section{Disclosure}

No potential conflicts of interest were disclosed.

\section{References}

[1] Mahjoub, M., Berenbaum, F. and Houard, X. (2012) Why Subchondral Bone in Osteoarthritis? The Importance of the Cartilage Bone Interface in Osteoarthritis. Osteoporosis International, 23, S841-S846. http://dx.doi.org/10.1007/s00198-012-2161-0

[2] Goldring, S.R. (2012) Alterations in Periarticular Bone and Cross Talk between Subchondral Bone and Articular Cartilage in Osteoarthritis. Therapeutic Advances in Musculoskeletal Diseases, 4, 249-258. http://dx.doi.org/10.1177/1759720X12437353

[3] Loeser, R.F., Goldring, S.R., Scanzello, C.R. and Goldring, M.B. (2012) Osteoarthritis: A Disease of the Joint as an Organ. Arthritis and Rheumatism, 64, 1697-1707. http://dx.doi.org/10.1002/art.34453

[4] Mutabaruka, M.S., Aoulad Aissa, M., Delalandre, A., Lavigne, M. and Lajeunesse, D. (2010) Local Leptin Production in Osteoarthritis Subchondral Osteoblasts May Be Responsible for Their Abnormal Phenotypic Expression. Arthritis Research and Therapy, 12, R20. http://dx.doi.org/10.1186/ar2925

[5] Gomez, R., Conde, J., Scotece, M., Gomez-Reino, J.J., Lago, F. and Gualillo, O. (2011) What's New in Our Understanding of the Role of Adipokines in Rheumatic Diseases? Nature Reviews Rheumatology, 7, 528-536. http://dx.doi.org/10.1038/nrrheum.2011.107

[6] Gabay, O. and Berenbaum, F. (2009) Adipokines in Arthritis: New Kids on the Block. Current Rheumatology Reviews, 5, 226-232. http://dx.doi.org/10.2174/157339709790192440

[7] Bijlsma, J.W., Berenbaum, F. and Lafeber, F.P. (2011) Osteoarthritis: An Update with Relevance for Clinical Practice. Lancet, 377, 2115-2126. http://dx.doi.org/10.1016/S0140-6736(11)60243-2

[8] Luk, T., Malam, Z. and Marshall, J.C. (2008) Pre-B Cell Colony-Enhancing Factor (PBEF)/Visfatin: A Novel Mediator of Innate Immunity. Journal of Leukocyte Biology, 83, 804-816. http://dx.doi.org/10.1189/jlb.0807581

[9] Gosset, M., Berenbaum, F., Salvat, C., Sautet, A., Pigenet, A., Tahiri, K. and Jacques, C. (2008) Crucial Role of Visfatin/Pre-B Cell Colony-Enhancing Factor in Matrix Degradation and Prostaglandin E2 Synthesis in Chondrocytes: Possible Influence on Osteoarthritis. Arthritis and Rheumatism, 58, 1399-1409. http://dx.doi.org/10.1002/art.23431

[10] Moschen, A.R., Kaser, A., Enrich, B., Mosheimer, B., Theurl, M., Niederegger, H. and Tilg, H. (2007) Visfatin, an Adipocytokine with Proinflammatory and Immunomodulating Properties. Journal of Immunology, 178, 1748-1758. http://dx.doi.org/10.4049/jimmunol.178.3.1748

[11] Faulk, C., Barks, A., Sanchez, B.N., Zhang, Z., Anderson, O.S., et al. (2014) Perinatal Lead (Pb) Exposure Results in Sex-Specific Effects on Food Intake, Fat, Weight, and Insulin Response across the Murine Life-Course. PLoS ONE, 9, e104273. http://dx.doi.org/10.1371/journal.pone.0104273

[12] Carmouche, J.J., Edward Puzas, J., Zhang, X., Tiyapatanaputi, P., Cory-Slechta, D.A., Robert Gelein, R., et al. (2005) Lead Exposure Inhibits Fracture Healing and Is Associated with Increased Chondrogenesis, Delay in Cartilage Mineralization, and a Decrease in Osteoprogenitor Frequency. Environmental Health Perspectives, 113, 749-755. http://dx.doi.org/10.1289/ehp.7596 
[13] ACR (2000) Recommendations for the Medical Management of Osteoarthritis of the Hip and Knee. Arthritis and Rheumatism, 43, 1905-1915. http://dx.doi.org/10.1002/1529-0131(200009)43:9<1905::AID-ANR1>3.0.CO;2-P

[14] Leng, S., McElhaney, J., Walston, J., Xie, D., Fedarko, N. and Kuchel, G. (2008) Elisa and Multiplex Technologies for Cytokine Measurement in Inflammation and Aging Research. Journal of Gerontology: Biological and Medical Sciences, 63, 879-884. http://dx.doi.org/10.1093/gerona/63.8.879

[15] Erel, O. (2004) A Novel Automated Direct Measurement Method for Total Antioxidant Capacity Using a New Generation, More Stable ABTS Radical Cation. Clinical Biochemistry, 37, 277-285. http://dx.doi.org/10.1016/j.clinbiochem.2003.11.015

[16] Fossati, P. and Prencipe, L. (1982) Measurement of Serum TG Colorimetrically with an Enzyme That Produce $\mathrm{H}_{2} \mathrm{O}_{2}$. Clinical Chemistry, 28, 2077-2080.

[17] Burstein, M., Scholink, H.R. and Morfin, R. (1970) Measurement of HDL-c in the Plasma with a Sensitive Colorimetric Method. Journal of Lipid Research, 19, 583.

[18] Trinder, P. (1969) Determination of Blood Glucose Using an Oxidase-Peroxidase System with a Non-Carcinogenic Chromogen. Journal of Clinical Pathology, 22, 158-161. http://dx.doi.org/10.1136/jcp.22.2.158

[19] Weykamp, C., John, W.G. and Mosca, A. (2009) A Review of the Challenge in Measuring Hemoglobin A1c. Journal of Diabetes Science and Technology, 3, 439-445. http://dx.doi.org/10.1177/193229680900300306

[20] Subramanian, K.S. and Meranger, J.C. (1981) A Rapid Electrothermal Atomic Absorption Spectrophotometric Method for Cadmium and Lead in Human Whole Blood. Clinical Chemistry, 27, 1866-1871.

[21] van der Helm-van Mil, A.H., van der Kooij, S.M., Allaart, C.F., Toes, R.E. and Huizinga, T.W. (2008) A High Body Mass Index Has a Protective Effect on the Amount of Joint Destruction in Small Joints in Early Rheumatoid Arthritis. Annals of the Rheumatic Diseases, 67, 769-674. http://dx.doi.org/10.1136/ard.2007.078832

[22] Gross, A.F., Fickert, S. and Gunther, K.P. (2005) Obesity and Arthritis. Orthopade, 34, 638-644.

[23] Felson, D.T., Anderson, J.J., Naimark, A., Walker, A.M. and Meenan, R.F. (1988) Obesity and Knee Osteoarthritis. The Framingham Study. Annals of Internal Medicine, 109, 18-24. http://dx.doi.org/10.7326/0003-4819-109-1-18

[24] Griffin, T.G., Huebner, J.L., Kraus, V.B., et al. (2012) Induction of Osteoarthritis and Metabolic Inflammation by a Very High-Fat Diet in Mice. Arthritis and Rheumatism, 64, 443-453. http://dx.doi.org/10.1002/art.33332

[25] Aspden, R.M. (2011) Obesity Punches above Its Weight in Osteoarthritis. Nature Reviews Rheumatology, 7, 65-68. http://dx.doi.org/10.1038/nrrheum.2010.123

[26] Mahmood, N.M.A. (2012) Relationship between Exposure to Petrol Products and the Trace Metal Status, Liver Toxicity and Hematological Markers in Gasoline Filling Workers in Sulaimani City. Journal of Environmental and Occupational Science, 1, 6-11. http://dx.doi.org/10.5455/jeos.20120419103934

[27] Agrawal, S., Bhatnagar, P. and Flora, S.J. (2015) Changes in Tissue Oxidative Stress, Brain Biogenic Amines and Acetylcholinesterase Following Co-Exposure to Lead, Arsenic and Mercury in Rats. Food Chemistry and Toxicology, 86, 208-216. http://dx.doi.org/10.1016/j.fct.2015.10.013

[28] Kawai, Y., Kubota, E. and Okabe, E. (2000) Reactive Oxygen Species Participation in Experimentally Induced Arthritis of the Temporomandibular Joint in Rats. Journal of Dental Research, 79, 1489-1495. http://dx.doi.org/10.1177/00220345000790071001

[29] Ghanwat, G.H., Patil, A.J., Patil, J.A., Kshirsagar, M.S., Sontakke, A. and Ayachit, R.K. (2015) Biochemical Effects of Lead Exposure on Oxidative Stress and Antioxidant Status of Battery Manufacturing Workers of Western Maharashtra, India. Journal of Basic and Clinical Physiology and Pharmacology, Published Online.

[30] Shlopov, B.V., Gumanovskaya, M.L. and Hasty, K.A. (2000) Autocrine Regulation of Collagenase 3 (Matrix Metalloproteinase 13) during Osteoarthritis. Arthritis and Rheumatism, 43, 195-205. http://dx.doi.org/10.1002/1529-0131(200001)43:1<195::AID-ANR24>3.0.CO;2-G 